Check for updates

Cite this: RSC Adv., 2019, 9, 39282

\title{
Adsorption and regeneration of leaf-based biochar for $p$-nitrophenol adsorption from aqueous solution
}

\author{
Hongfang $\mathrm{Ma}$, (D) *ab Zhaogui Xu, ${ }^{\mathrm{b}}$ Wenyu Wang, ${ }^{\mathrm{b}}$ Xiang Gao ${ }^{\mathrm{c}}$ and Huifang $\mathrm{Ma}^{\mathrm{b}}$
}

As an environmentally friendly and low-cost adsorbent, biochar has great potential in wastewater treatment. This study investigated biochar derived from Platanus orientalis L. leaves (PLB) activated by $\mathrm{KOH}$ in terms of its capacity and reusability to adsorb $p$-nitrophenol (PNP). PLB had a large specific surface area and total pore volume, and exhibits good PNP removal with a maximal adsorption capacity of $622.73 \mathrm{mg} \mathrm{g}^{-1}$ at $298 \mathrm{~K}$. Batch experiments showed that PLB had a high PNP adsorption capacity under acidic conditions. Experimental results were well described by the pseudo-second-order kinetic model and the Langmuir adsorption isotherm model. The thermodynamic study showed that PNP adsorption was a spontaneously exothermic process, and increasing temperature was not conducive to adsorption. In addition, PNP adsorption was mainly attributed to hydrophobic interaction. The regeneration experiment showed that PLB had good reusability. After the fifth regeneration, the adsorption capacity of PLB still reached $557.05 \mathrm{mg} \mathrm{g}^{-1}$. The deactivation of oxygen-containing functional groups and pore blockage were the causes for the decrease in adsorption capacity of the recycled PLB. Moreover, the biochar showed good adsorption efficiency and reusability, thereby suggesting its potential to serve as an efficient PNP adsorbent for wastewater treatment.

Received 30th September 2019 Accepted 21st November 2019

DOI: 10.1039/c9ra07943b

rsc.li/rsc-advances adsorption by an appropriate adsorbent has shown excellent effect of PNP removal.

Carbon materials have received considerable attention in PNP removal due to their surface functional groups and welldeveloped porosity, ${ }^{13}$ which can be produced from all types of carbon-containing substances, including biomass waste, ${ }^{14}$ coal,${ }^{15,16} \beta$-cyclodextrin, ${ }^{17}$ resin, ${ }^{18}$ and petroleum waste. ${ }^{19} \mathrm{Among}$ these materials, the preparation of biomass carbon materials is attractive in terms of cost and environmental management, including pollutant and solid waste treatments. In the past few years, many biomass carbon materials have been prepared to remove PNP from wastewater. For example, Fe/Zn biochar made from sawdust with a maximal PNP adsorption capacity of $170.0 \mathrm{mg} \mathrm{g}^{-1}$ showed good adsorption performance compared with P-biochar, Zn-biochar and Fe-biochar. ${ }^{20}$ Zheng et al. ${ }^{21}$ found that microalgal biochars prepared from Chlorella sp. Cha-01 showed higher PNP adsorption capability $\left(204.8 \mathrm{mg} \mathrm{g}^{-1}\right)$ than two other types of microalgal biochars. Various efforts have been undertaken to remove PNP with biochar. On this basis, it is still necessary to actively explore a technology that has a wider source of raw materials and a more simplified preparation process to further improve the adsorption capacity. In this research, Platanus orientalis L. (Platanus) leaves, with the advantage of easy availability and large quantity, were used to prepare biochar for wastewater treatment.

The activation of biomass plays a crucial role in the improvement of porosity and specific surface area. Chemical 
activation is widely used because of its short activation time, low activation temperature and simple control process. In addition, there will be gases or compounds generated in the reaction between activator and biomass during the chemical activation process, and the porous structure of biochar will be formed after leaching. ${ }^{22}$ For the preparation of high porosity and large specific surface area biochars, researchers have investigated many chemical activation agents, such as $\mathrm{KOH}$, $\mathrm{NaOH}, \mathrm{K}_{2} \mathrm{CO}_{3}, \mathrm{ZnCl}_{2}, \mathrm{H}_{3} \mathrm{PO}_{4}$ and $\mathrm{H}_{2} \mathrm{SO}_{4}$, etc. ${ }^{2,24}$ Among these available activation agents, $\mathrm{KOH}$ is more suitable for making biochar with high microporosity, and the prepared biochar has a larger specific surface area. ${ }^{\mathbf{2 4 - 2 6}}$ Hence, $\mathrm{KOH}$ was selected as activation agent.

In addition, the extent of adsorbent regeneration is important in adsorption due to its low cost and sustainability. Common regeneration techniques of carbon materials in industries are based on thermal and chemical methods. ${ }^{27}$ Thermal regeneration is a widely used method, but it has several drawbacks, such as high energy consumption, high cost and significant deterioration of the pore structure.$^{28}$ By contrast, chemical regeneration usually leads to zero carbon attrition, which results in high recovery of adsorption capacities. ${ }^{29}$ Alkali is a type of traditional chemical reagent used in the regeneration of carbon materials. The adsorption capacity of regenerated carbon materials by alkali solution will decrease, ${ }^{30}$ but the causes for the decline are not well investigated. Thus, considerable research should be conducted to determine the causes of the reduction of the adsorption capacity of chemicalrecycled biochars.

In this study, Platanus leaves were used as the precursor in preparing carbon materials (PLB) through $\mathrm{KOH}$ chemical activation to minimize the energy consumption during biochar preparation. The biochar was characterized to explain its physicochemical properties and illustrate its adsorption characteristics for PNP. The kinetics, isothermal adsorption and thermodynamics were evaluated to explain the adsorption mechanism. In addition, the reproducibility and causes for the decrease in PNP adsorption of the chemical-recycled biochar were investigated.

\section{Materials and methods}

\subsection{Materials}

The leaves were collected and thoroughly washed to remove the attached soils and plant residues, and then they were dried in an oven and ground into powder. The powder was mixed with $\mathrm{KOH}$ (activating agent) at an impregnation ratio of $1: 1$ (g $\mathrm{KOH}: \mathrm{g}$ leaves powder) in a certain amount of distilled water. The mixture was oscillated to a homogeneous phase and dried in the oven for several hours at $80{ }^{\circ} \mathrm{C}$, and then transferred to porcelain boats and heated in a tube furnace under a $\mathrm{N}_{2}$ flow. The heating procedure was abided by the following stages at a heating rate of $5{ }^{\circ} \mathrm{C} \mathrm{min}{ }^{-1}$ : first at $450{ }^{\circ} \mathrm{C}$ for $30 \mathrm{~min}$, second at $650{ }^{\circ} \mathrm{C}$ for $30 \mathrm{~min}$, and finally at $800{ }^{\circ} \mathrm{C}$ for $1 \mathrm{~h} .{ }^{31}$ After cooling to room temperature, the resulting mixture was washed with diluted $\mathrm{HCl}$, and then cleaned with boiled distilled water until the $\mathrm{pH}$ of the filtrate became neutral. Moreover, the final product was dried and marked as PLB. The leaves biochar was prepared with the same pyrolysis procedures and labeled was marked as LB.

\subsection{Characterization methods}

The surface morphology of the biochar was characterized by using a scanning electron microscope (SEM, Regulus8220, Japan). A Fourier transform infrared spectrometer (FTIR, IRAffinity-1S WL, Shimadzu Corporation, Japan) was used to show the functional groups presented on the biochar surface in wave number ranging from $4000 \mathrm{~cm}^{-1}$ to $400 \mathrm{~cm}^{-1}$. The chemical composition and element states of the biochar surface were identified through X-ray photoelectron spectroscopy (XPS, Escalab 250Xi, USA). Nitrogen adsorption-desorption isotherm measurement was performed by using a volumetric adsorption analyzer (JW-BK300C, JWGB SCI. \& TECH., Beijing) at $77 \mathrm{~K}$. The specific surface area calculated by using Brunauer-EmmettTeller (BET) method, and the pore size distributions evaluated by using Horvath-Kawazoe and Barrett-Joyner-Halenda models for micropores and mesopores, respectively.

The point of zero charge $\left(\mathrm{pH}_{\mathrm{PZC}}\right)$ of $\mathrm{PLB}$ was determined using $0.1 \mathrm{M} \mathrm{NaCl}$ at $\mathrm{pH} \mathrm{2,4,6,8,10,} \mathrm{and} \mathrm{12,} \mathrm{and} \mathrm{the} \mathrm{pH}$ values were adjusted with $0.1 \mathrm{M} \mathrm{HCl}$ and $0.1 \mathrm{M} \mathrm{NaOH}$. Each $\mathrm{NaCl}(20$ $\mathrm{mL}$ ) with different values of $\mathrm{pH}$ was mixed with $0.02 \mathrm{~g}$ of PLB, and the mixture was stirred for $24 \mathrm{~h}$. After standing for $30 \mathrm{~min}$, the $\mathrm{pH}$ of the supernatant was measured. The $\mathrm{pH}_{\mathrm{PZC}}$ value was obtained from a plot of the supernatant $\mathrm{pH}\left(\mathrm{pH}_{\mathrm{f}}\right)$ against the initial $\mathrm{pH}$ value $\left(\mathrm{pH}_{\mathrm{i}}\right){ }^{32}$

\subsection{Adsorption experiments}

Various batch experiments investigated the effects of $\mathrm{pH}$, PLB dosage, reaction time, initial PNP concentration, and system temperature on PNP adsorption. To evaluate the $\mathrm{pH}$ effect, $20 \mathrm{~mL}$ of PNP solution (300 $\mathrm{mg} \mathrm{L}^{-1}$ ) and $20 \mathrm{mg}$ of PLB were mixed. The pH was adjusted with $0.1 \mathrm{M} \mathrm{HCl}$ or $0.1 \mathrm{M} \mathrm{NaOH}$. Then, the mixture was sealed and oscillated at a constant speed of $150 \mathrm{rpm}$ in a reciprocating oscillator (THZ-82, Hualin Industrial Co., Ltd. Shanghai) at $298 \mathrm{~K}$. After filtration, the PNP concentration in the filtrate was measured by a UV spectrophotometer (723PC, Phoenix Optical Instrument Co., Ltd. Shanghai) at a wavelength of $317 \mathrm{~nm}$. The removal efficiency $(\omega)$ and the amounts of PNP adsorbed $\left(q, \mathrm{mg} \mathrm{g}^{-1}\right)$ on PLB were calculated using eqn (1) and (2).

$$
\begin{gathered}
\omega(\%)=\left(C_{0}-C_{t}\right) / C_{0} \times 100 \% \\
q=\left(C_{0}-C_{t}\right) \times V / m
\end{gathered}
$$

where $C_{0}\left(\mathrm{mg} \mathrm{L}^{-1}\right)$ and $C_{t}\left(\mathrm{mg} \mathrm{L}^{-1}\right)$ represent PNP concentrations in the solution at initial and time $t$, respectively. $V(\mathrm{~L})$ is the volume of the solution, and $m(\mathrm{~g})$ is the weight of PLB. An optimum $\mathrm{pH}$ condition was selected on the basis of the results to conduct other experiments.

The effect of PLB dosage on the removal of PNP was conducted by adding various amounts (0.010-0.035 g) of PLB into PNP solution (300 $\mathrm{mg} \mathrm{L}^{-1}, \mathrm{pH}=3$ ) at a constant speed of 
$150 \mathrm{rpm}$ at $298 \mathrm{~K}$ for $240 \mathrm{~min}$. To evaluate the reaction time effect, the mixture was sealed and oscillated at constant speed of $150 \mathrm{rpm}$ at $298 \mathrm{~K}$ for $10-720 \mathrm{~min}$ before filtration. The experiment procedure and other conditions were the same as the study on $\mathrm{pH}$ effect. Different initial concentrations of PNP and reaction temperature were assessed in conducting the adsorption isotherm and thermodynamic studies. The mixture of $20 \mathrm{mg}$ PLB and $20 \mathrm{~mL}$ PNP with different concentrations (100 $\mathrm{mg} \mathrm{L}^{-1}$ to $2000 \mathrm{mg} \mathrm{L}^{-1}, \mathrm{pH}=3$ ) was oscillated at desired temperatures $(298,313$, and $328 \mathrm{~K}$ ) at a speed of $150 \mathrm{rpm}$ and reaction time of $180 \mathrm{~min}$. The experiment procedure and other conditions were the same as the study on $\mathrm{pH}$ effect.

\subsection{Regeneration experiment}

The solid-liquid (PLB and PNP solutions) ratio was set to 1 $\left(\mathrm{g} \mathrm{L}^{-1}\right.$ ), with an initial PNP concentration of $1800 \mathrm{mg} \mathrm{L}^{-1}$. The adsorption reached equilibrium after $3 \mathrm{~h}$ at $298 \mathrm{~K}$ with a shaking speed of $150 \mathrm{rpm}$. The equilibrium concentration was measured, and the PLB was separated from the solution with a filter $(0.22$ $\mu \mathrm{m})$. The collected PLB was washed several times with $1 \mathrm{M} \mathrm{NaOH}$ and distilled water until neutral. After drying at $80{ }^{\circ} \mathrm{C}$, the recycled biochar was used for the next adsorption process (Fig. 1). In total, 7 times of biochar regeneration with the original biochar (PLB) were performed to determine the adsorption capacity of PNP. Moreover, the first generation of recycled biochar was denoted as R1, and the next six generations were noted as R2, R3, R4, R5, R6, and R7, respectively. Several typical generations, such as PLB, R4, and R6 for the textural parameters and PLB and R6 for the FTIR spectra, were used and analyzed the causes of decline in adsorption capacity after regeneration.

\subsection{Statistical analysis}

The figures for $\mathrm{pH}$ effect on PNP removal rate and the recycle times on adsorption effect presented the mean value of

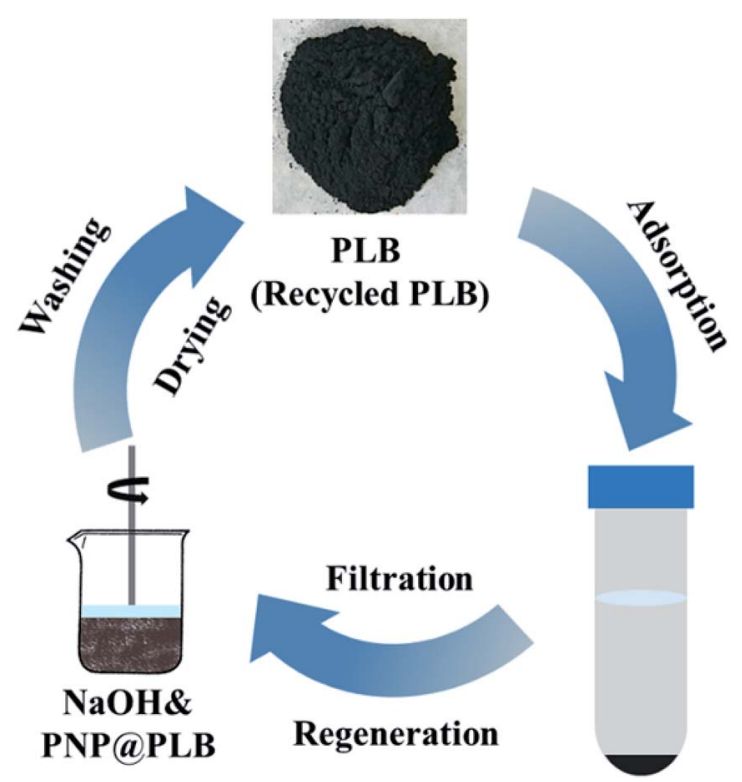

Fig. 1 The demonstration of the adsorption and regeneration process of PLB. triplicate, and statistical analyses (ANOVA) and LSD test for mean comparisons were conducted in SPSS 17.0. Differences at $P \leq 0.05$ were considered significant.

\section{Results and discussion}

\subsection{Characterizations of biochar}

The leaf-based biochar prepared in this study had a porous structure (Fig. 2a), which could be explained by the following reaction (eqn. (3)-(8)) of $\mathrm{KOH}$ with the leaf powder during pyrolysis: $^{33,34}$

$$
\begin{gathered}
6 \mathrm{KOH}+2 \mathrm{C} \rightarrow 2 \mathrm{~K}+3 \mathrm{H}_{2}+2 \mathrm{~K}_{2} \mathrm{CO}_{3} \\
\mathrm{~K}_{2} \mathrm{CO}_{3}+\mathrm{C} \rightarrow \mathrm{K}_{2} \mathrm{O}+2 \mathrm{CO} \\
\mathrm{K}_{2} \mathrm{CO}_{3} \rightarrow \mathrm{K}_{2} \mathrm{O}+\mathrm{CO}_{2} \\
2 \mathrm{~K}+\mathrm{CO}_{2} \rightarrow \mathrm{K}_{2} \mathrm{O}+\mathrm{CO} \\
\mathrm{K}_{2} \mathrm{CO}_{3}+2 \mathrm{C} \rightarrow 2 \mathrm{~K}+3 \mathrm{CO} \\
\mathrm{CO}_{2}+\mathrm{C} \rightarrow 2 \mathrm{CO}
\end{gathered}
$$

Hydrogen, carbon monoxide, potassium vapor, and carbon dioxide were generated during sintering, which resulted in a large number of pores on the biochar surface. In addition, $\mathrm{K}_{2} \mathrm{CO}_{3}$ and other compounds were washed away with diluted $\mathrm{HCl}$ and the micropores formed on biochar. Therefore, this process increased the specific surface area and pore volume of the biochar, which can be beneficial for PNP adsorption.

The FTIR spectra of PLB and PLB after PNP adsorption (PNP@PLB) were shown in Fig. 2b. The bands of PLB at $1744 \mathrm{~cm}^{-1}$ and $1690 \mathrm{~cm}^{-1}$ were the $\mathrm{C}=\mathrm{O}$ stretching vibration, and the band at $1524 \mathrm{~cm}^{-1}$ was the aromatic $\mathrm{C}=\mathrm{C}$ stretching vibration. ${ }^{35}$ The band at $1134 \mathrm{~cm}^{-1}$ might have contributions from $\mathrm{C}-\mathrm{O}$ telescopic vibration in ester group, ether group, aliphatic ether and carboxylic acid groups. Moreover, the band at $1003 \mathrm{~cm}^{-1}$ could be assigned to $\mathrm{O}-\mathrm{H}$ bending vibration in alcoholic, phenolic and carboxylic acid groups. These results indicated that PLB surface existed some oxygen-containing functional groups of $-\mathrm{OH},-\mathrm{COOH}$ and $-\mathrm{C}-\mathrm{O}-\mathrm{C}$. The peaks of the ring $\mathrm{C}-\mathrm{H}$ vibrations appeared at $798 \mathrm{~cm}^{-1}$ and $675 \mathrm{~cm}^{-1} .^{36}$ The broad band of PNP@PLB at $3456 \mathrm{~cm}^{-1}$ was related to the O-H stretching vibration peak of phenolic hydroxyl. ${ }^{37}$ The band of the symmetrical stretching vibration of aromatic $-\mathrm{NO}_{2}$ appeared at $1331 \mathrm{~cm}^{-1} \cdot{ }^{38}$ In addition, no peak was observed at $1134 \mathrm{~cm}^{-1}$ of PNP@PLB compared to PLB, which might be attributed to the hydrogen bonding between the oxygencontaining functional groups of PLB and PNP. The FTIR spectra of PNP showed the broad band at $3321 \mathrm{~cm}^{-1}$ was related to the $\mathrm{O}-\mathrm{H}$ stretching vibration peak, and the peak at $1218 \mathrm{~cm}^{-1}$ was related to the aromatic $-\mathrm{NO}_{2} \cdot{ }^{39}$ The peaks at 3321 and $1218 \mathrm{~cm}^{-1}$ shifted to 3456 and $1331 \mathrm{~cm}^{-1}$ of PNP@PLB, respectively, which indicated the hydrogen bonding between PNP and PLB. ${ }^{32}$ These characteristics indicated the successful adsorption of PNP molecules on PLB through hydrogen 

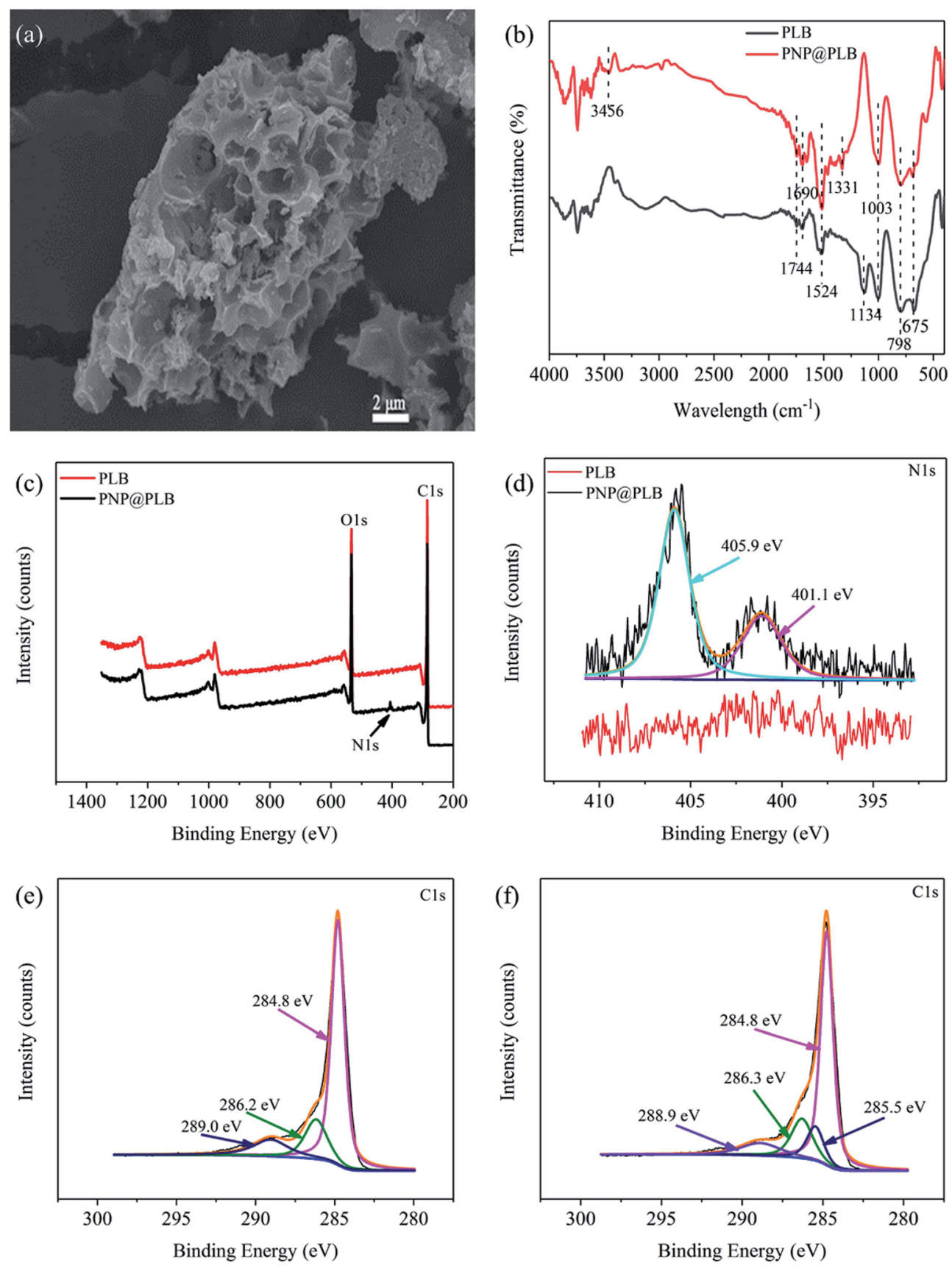

Fig. 2 SEM image of PLB (a), The FTIR spectra of PLB and PNP@PLB (b), the XPS spectra of PLB and PNP@PLB (c), N 1s XPS spectra of PNP(aPLB (d), C 1s XPS spectra of PLB (e) and PNP@PLB (f).

bonding between the hydroxyl groups or carboxyl groups on PLB and the hydroxyl, nitro groups of PNP.

The XPS spectra of PLB and PNP@PLB were shown in Fig. 2c-f. The survey scan spectra of PLB and PNP@PLB demonstrated the existence of $\mathrm{O} 1 \mathrm{~s}$ and $\mathrm{C} 1 \mathrm{~s}$, and a new peak corresponding to N 1s was generated in PNP@PLB (Fig. 2c). Two new peaks at $401.1 \mathrm{eV}$ and $405.9 \mathrm{eV}$, which corresponded to $\mathrm{C}-\mathrm{N}$ and nitro group, ${ }^{\mathbf{4 0 , 4 1}}$ were generated in the $\mathrm{N}$ 1s spectra of PNP@PLB (Fig. 2d). The C 1s spectra of PLB (Fig. 2e) could be fitted into three peaks, including $284.8 \mathrm{eV}(\mathrm{C}-\mathrm{C}), 286.2 \mathrm{eV}(\mathrm{C}-\mathrm{O})$, and $289.0 \mathrm{eV}(\mathrm{O}=\mathrm{C}-\mathrm{O}) .{ }^{42}$ The peaks of $\mathrm{C}-\mathrm{C}, \mathrm{C}-\mathrm{O}$, and $\mathrm{O}=\mathrm{C}-\mathrm{O}$ remained essentially unchanged in the $\mathrm{C}$ 1s spectra of PNP@PLB (Fig. 2f), with a new peak generated at $285.5 \mathrm{eV}(\mathrm{C}-\mathrm{N})$ compared with that of PLB. ${ }^{43}$ These observations confirmed the PNP adsorption on PLB, which was consistent with the discussion in the FTIR analysis.

Adsorption/desorption isotherm analysis showed that LB, PLB and PNP@PLB exhibited a type-IV isotherm (Fig. 3 and Fig. 4a and b, respectively). The curves rapidly increased at low relative pressure, which demonstrated the existence of micropores. Moreover, hysteresis loops could be found at medium relative pressure, indicating the presence of mesopores. ${ }^{44}$ The 


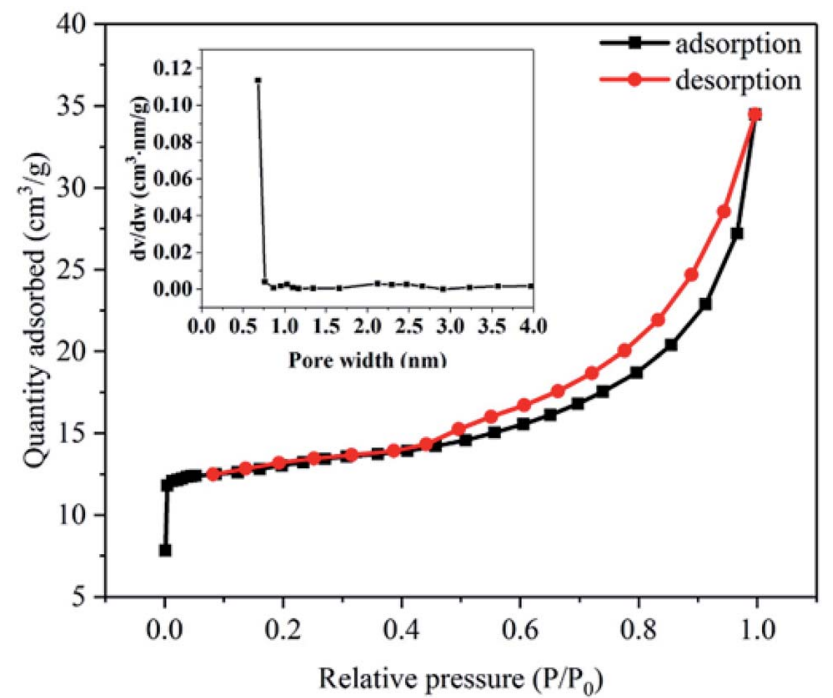

Fig. $3 \mathrm{~N}_{2}$ adsorption/desorption isotherm of $L B$, the inset is the corresponding pore size distribution.

most probable apertures of LB, PLB and PLB@PNP were $0.68 \mathrm{~nm}, 0.60 \mathrm{~nm}$ and $0.45 \mathrm{~nm}$, as shown in the insets. In addition, the average pore diameters of LB, PLB and PLB@PNP were $3.91 \mathrm{~nm}, 2.23 \mathrm{~nm}$ and $2.24 \mathrm{~nm}$, respectively. Table 1 showed that the BET surface area and the total pore volume of LB were $52.05 \mathrm{~m}^{2} \mathrm{~g}^{-1}$ and $0.05 \mathrm{~cm}^{3} \mathrm{~g}^{-1}$, which were $1792.38 \mathrm{~m}^{2}$ $\mathrm{g}^{-1}$ and $0.94 \mathrm{~cm}^{3} \mathrm{~g}^{-1}$ for $\mathrm{PLB}$, respectively. The activation process greatly improved the specific surface area and pore volume of biochar, and provided more adsorption sites for the removal of PNP. Hence, PLB was selected as adsorbent to conduct adsorption experiments. In addition, the proportion of micropore surface area and micropore volume reached to $88.27 \%$ and $75.53 \%$, causing micropores greatly improved the BET surface area of PLB. Furthermore, compared with the PLB, the BET surface area and micropores volume of PNP@PLB remarkably changed, whereas macropores and mesopores only showed a slight change. This indicated that the micropores played a major role in PNP adsorption, and the macropores and
Table 1 The textural parameters of $L B, P L B$ and PLB after PNP adsorption (PNP@PLB)

\begin{tabular}{lrrrrrl}
\hline $\begin{array}{l}\text { Carbon } \\
\text { material }\end{array}$ & $\begin{array}{l}S_{\mathrm{BET}}{ }^{a} \\
\left(\mathrm{~m}^{2} \mathrm{~g}^{-1}\right)\end{array}$ & $\begin{array}{c}S_{\text {mic }}{ }^{b} \\
\left(\mathrm{~m}^{2} \mathrm{~g}^{-1}\right)\end{array}$ & $\begin{array}{c}S_{\text {mac\&mes }}{ }^{c} \\
\left(\mathrm{~m}^{2} \mathrm{~g}^{-1}\right)\end{array}$ & $\begin{array}{l}V_{\text {tot }}{ }^{d} \\
\left(\mathrm{~cm}^{3} \mathrm{~g}^{-1}\right)\end{array}$ & $\begin{array}{l}V_{\text {mic }}{ }^{e} \\
\left(\mathrm{~cm}^{3} \mathrm{~g}^{-1}\right)\end{array}$ & $\begin{array}{l}V_{\text {mac\&mes }}{ }^{f} \\
\left(\mathrm{~cm}^{3} \mathrm{~g}^{-1}\right)\end{array}$ \\
\hline LB & 52.05 & 42.25 & 9.80 & 0.05 & 0.02 & 0.03 \\
PLB & 1792.38 & 1582.13 & 210.25 & 0.94 & 0.71 & 0.23 \\
PNP@PLB & 375.75 & 261.32 & 114.43 & 0.33 & 0.15 & 0.18
\end{tabular}

${ }^{a} S_{\text {BET }}$ : BET surface area. ${ }^{b} S_{\text {mic }}$ : micropore surface area. ${ }^{c} S_{\text {mac\&mes: }}$ : macropore and mesopore surface area. ${ }^{d} V_{\text {tot }}$ : total pore volume. ${ }^{e} V_{\text {mic }}$ : micropore volume. ${ }^{f} V_{\text {mac\&mes }}$ : macropore and mesopore volume.

mesopores had a minor effect. These results indicated that the proportion of micropores in biochar had the better PNP adsorption.

\subsection{Effect of pH on PNP adsorption}

The removal efficiency of PNP decreased with the increase of $\mathrm{pH}$, and the highest point was occurred at pH 3 (Fig. 5a). On this basis, other adsorption and regeneration experiments were conducted with optimized $\mathrm{pH}$ of PNP at 3. At low $\mathrm{pH}$ condition, PNP in the solution mainly existed in a molecular form, and PNP removal might be ascribed to the hydrogen bond, hydrophobic interaction, and $\pi-\pi$ interaction. ${ }^{45}$ From Fig. $5 \mathrm{~b}, \mathrm{pH}_{\mathrm{PZC}}$ was approximately 4.77 , which was higher than the optimized $\mathrm{pH}$ for PNP adsorption, illustrating that the main interaction between PNP and PLB were not hydrogen bonding. In addition, the electron acceptor $-\mathrm{NO}_{2}$ of PNP and the small amount of oxygen-containing functional groups on the PLB surface reduced the electron density of aromatic ring and basal planes, which led to a weak $\pi-\pi$ interaction. ${ }^{46}$ These observations suggested that PNP adsorption on PLB was mainly attributed to hydrophobic interaction. However, the removal rate sharply decreased at high $\mathrm{pH}$ condition. The reason was that the surface charge of the biochar was negative when $\mathrm{pH}$ was higher than $\mathrm{pH}_{\mathrm{PZC}}$, and considerable PNPs were ionized as the $\mathrm{pH}$ increased. Thus, electrostatic repulsion occurred between the surface of PLB and PNP ions, resulting in a sharp decrease.
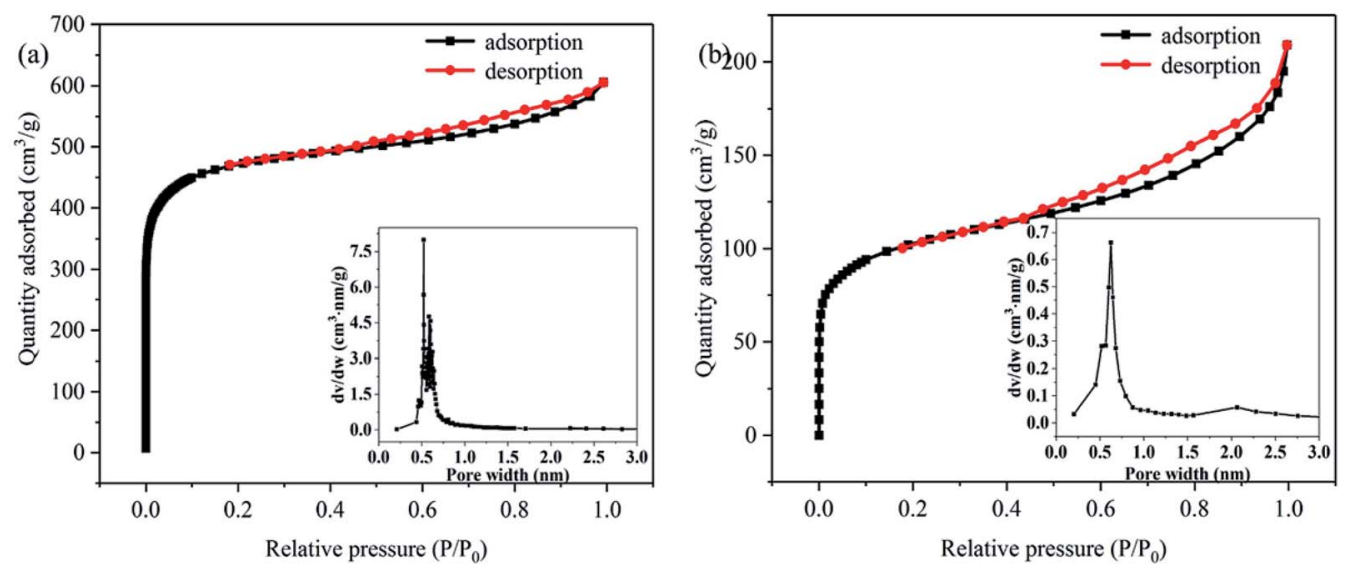

Fig. $4 \quad \mathrm{~N}_{2}$ adsorption/desorption isotherm of PLB (a) and PNP@PLB (b), the inset is the corresponding pore size distribution. 

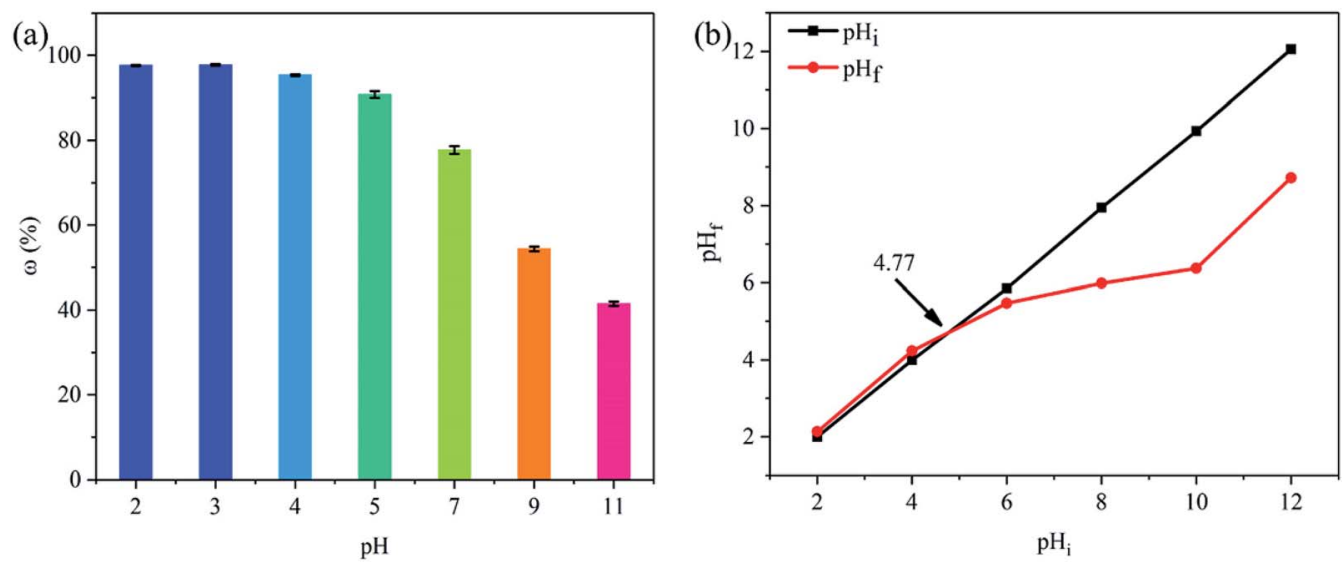

Fig. 5 Effect of initial pH of PNP removal efficiency (a), determination of the $\mathrm{pH}_{\mathrm{PZC}}$ for PLB via $\mathrm{pH}$ drift method (b).

\subsection{Effect of PLB dosage on PNP adsorption}

Fig. 6 showed that the removal efficiency of PNP obviously increased when the PLB dosage ranged from 0.01 to $0.02 \mathrm{~g}$. As the PLB dosage increased, the increase of adsorption sites caused the increase of adsorption efficiency. Subsequently, the removal efficiency maintained basically unchanged when the PLB dosage ranged from 0.02 to $0.035 \mathrm{~g}$. This may be related to the adsorbent aggregation. The adsorption capacity of PNP decreased from 444.46 to $163.34 \mathrm{mg} \mathrm{g}^{-1}$ when the PLB dosage ranged from 0.01 to $0.035 \mathrm{~g}$. According to as the factor of cost, adsorption capacity and removal rate, the optimum dosage of PLB was selected to be $0.02 \mathrm{~g}$.

\subsection{Adsorption kinetics}

Fig. 7a showed that the adsorption capacity of PNP rapidly increased within $5 \mathrm{~min}$. And the adsorption capacity remarkably increased with the extension time of $180 \mathrm{~min}$, adsorption capacity of $291.80 \mathrm{mg} \mathrm{g}^{-1}$, and removal rate of $97.27 \%$. Subsequently, the adsorption capacity approximately leveled off,

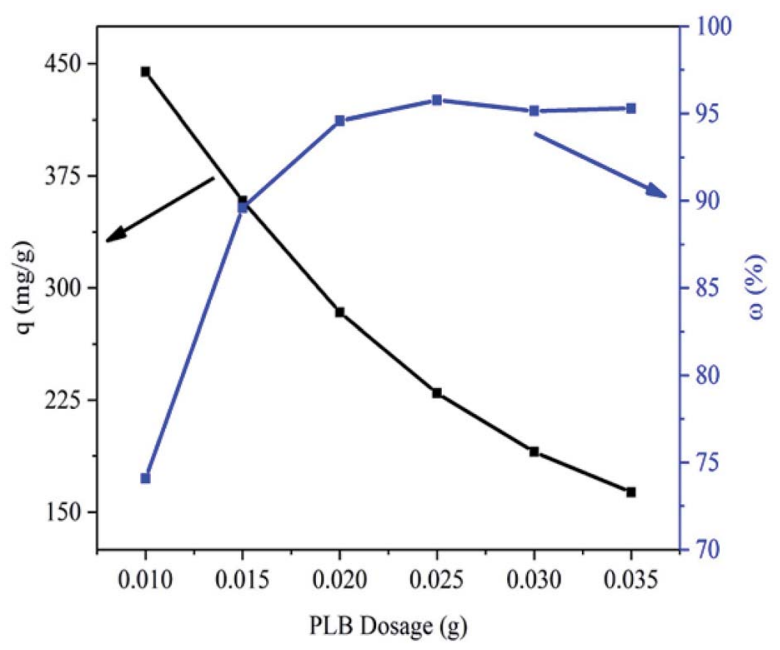

Fig. 6 Effect of PLB dosage $(0.010-0.035 \mathrm{~g})$ on PNP removal. which indicated the adsorption experiment reached equilibrium at $180 \mathrm{~min}$.

Adsorption kinetics is a fundamental aspect for evaluating the adsorption process. The kinetic models for PNP adsorption on PNP were investigated by using pseudo-first-order kinetic (9) and pseudo-second-order kinetic models (10), ${ }^{47}$ and the diffusion mechanism was described by using an intra-particle diffusion model (11). ${ }^{48}$

$$
\begin{gathered}
\ln \left(q_{\mathrm{e}}-q_{\mathrm{t}}\right)=\ln q_{\mathrm{e}}-K_{1} t \\
t / q_{\mathrm{t}}=1 /\left(K_{2} q_{\mathrm{e}}^{2}\right)+t / q_{\mathrm{e}} \\
q_{t}=K_{\mathrm{id}} t^{1 / 2}+C_{\mathrm{i}}
\end{gathered}
$$

where $q_{\mathrm{e}}\left(\mathrm{mg} \mathrm{g}^{-1}\right)$ is the amount of PNP adsorbed at equilibrium, and $q_{\mathrm{t}}\left(\mathrm{mg} \mathrm{g}^{-1}\right)$ represents the amount of PNP adsorbed at time $t(\min ) . K_{1}\left(\min ^{-1}\right)$ and $K_{2}\left(\mathrm{~g}(\min \mathrm{mg})^{-1}\right)$ are the rate constants for the pseudo-first and pseudo-second order adsorption kinetic models, respectively. $K_{\mathrm{id}}\left(\mathrm{mg}\left(\mathrm{g}^{-1} \mathrm{~min}^{-1 / 2}\right)\right)$ is the diffusion rate constant, and $C_{\mathrm{i}}$ is a constant related to the boundary layer thickness.

The correlation coefficients of the dynamic model for PNP adsorption on PLB were obtained from Fig. $7 \mathrm{~b}$ and $\mathrm{c}$, and Table 2 listed the dynamic fitting parameters. The correlation coefficient showed that the experimental data fitted better with the pseudo-second-order kinetic model $\left(R^{2}=0.9998\right)$ than with the pseudo-first-order kinetic model $\left(R^{2}=0.9887\right)$. In addition, the adsorption capacity calculated from the pseudo-second-order kinetic model $\left(q_{\mathrm{e} 2 \text {,cal }}=294.12 \mathrm{mg} \mathrm{g}^{-1}\right)$ was approximately consistent with $q_{\mathrm{e}}$,exp, which were considerably higher than that calculated from the pseudo-first-order kinetic equation $\left(q_{\mathrm{e} 1, \mathrm{cal}}=\right.$ $\left.38.64 \mathrm{mg} \mathrm{g}^{-1}\right)$. Therefore, PNP adsorption followed the pseudosecond-order kinetic model.

Fig. 7d showed that PNP adsorption could be described by three linear sections, indicating the occurrence of multiple stages during adsorption. In the first stage, the adsorption mainly occurred on the external surface, where approximately $90 \%$ of PNP molecules were adsorbed from the solution to the external surface. In the second stage, the adsorption reaction 

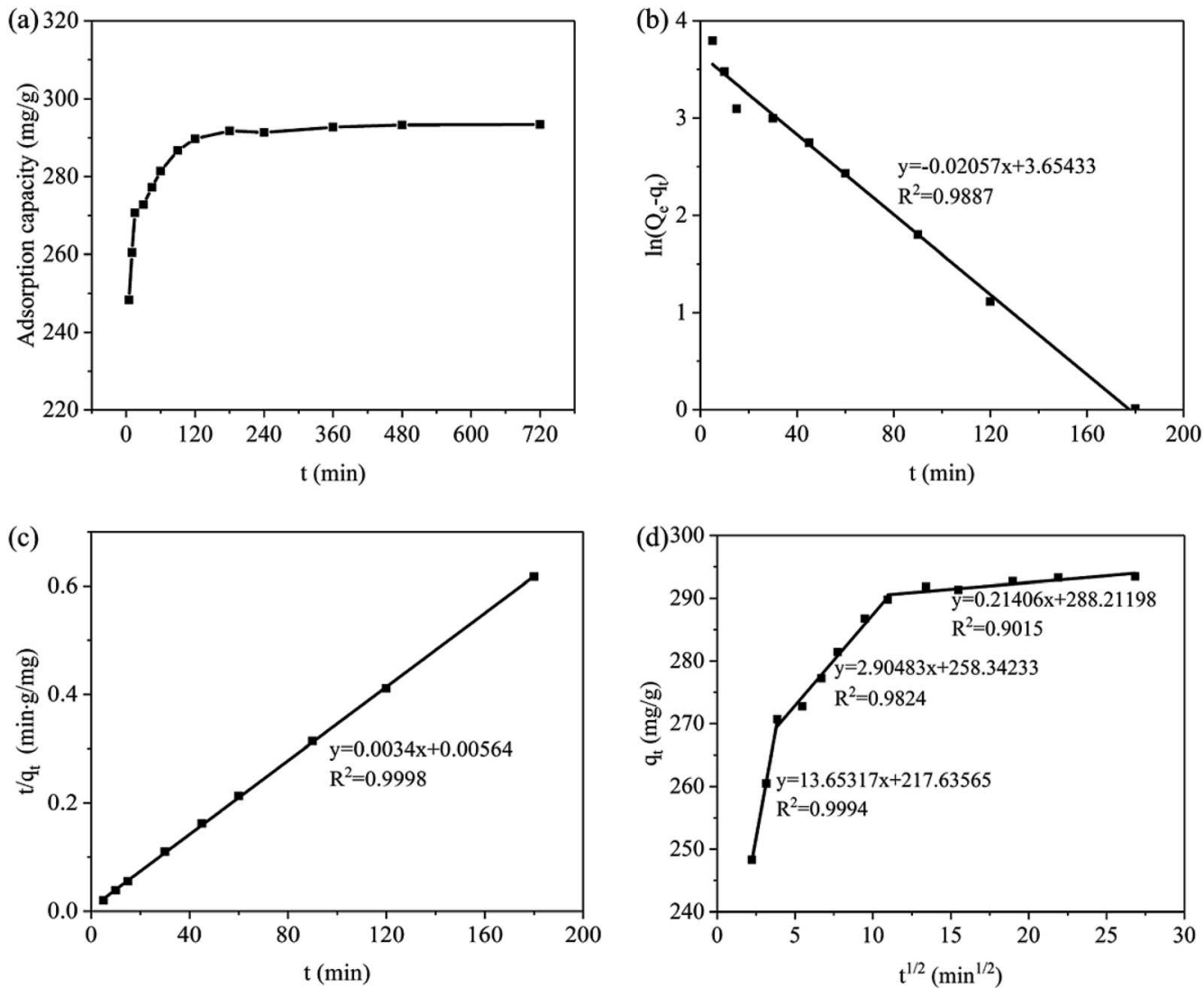

Fig. 7 Effect of reaction time on PNP adsorption (a); Pseudo-first-order kinetic model (b); Pseudo-second-order kinetic model (c); Intra-particle diffusion model (d).

rate decreased, and the PNP molecules on the external surface diffused into PLB pores as the adsorption process progresses. In the last stage, the adsorption reaction reached equilibrium.

\subsection{Adsorption isotherm and thermodynamic studies}

Three adsorption isotherms (Langmuir, Freundlich, and Temkin models) were used to investigate the reaction behavior between the PNP molecules and PLB. The Langmuir isotherm model assumes that the adsorbate molecules form a monolayer on adsorbents with homogeneous surface, and Freundlich

Table 2 Adsorption kinetic parameters of PNP adsorbed on PLB

\begin{tabular}{llc}
\hline & \multicolumn{2}{l}{ Parameter } \\
\cline { 2 - 3 } Model & $q_{\mathrm{e}, \exp }\left(\mathrm{mg} \mathrm{g}^{-1}\right)$ & 292.81 \\
\hline Pseudo-first-order kinetics model & $q_{\mathrm{e} 1, \mathrm{cal}}\left(\mathrm{mg} \mathrm{g}^{-1}\right)$ & 38.64 \\
& $K_{1}\left(\mathrm{~min}^{-1}\right)$ & 0.0206 \\
& $R^{2}$ & 0.9887 \\
Pseudo-second-order kinetics & $q_{\mathrm{e} 2 \text {,cal }}\left(\mathrm{mg} \mathrm{g}^{-1}\right)$ & 294.12 \\
model & $K_{2}\left(\mathrm{~g}\left(\mathrm{~min}^{-1} \mathrm{mg}^{-1}\right)\right)$ & 0.0021 \\
Intra-particle diffusion model & $R^{2}$ & 0.9998 \\
& $K_{1 \mathrm{~d}}\left(\mathrm{mg}\left(\mathrm{g}^{-1} \mathrm{~min}^{-1 / 2}\right)\right)$ & 13.6532 \\
& $K_{2 \mathrm{~d}}\left(\mathrm{mg}\left(\mathrm{g}^{-1} \mathrm{~min}^{-1 / 2}\right)\right)$ & 2.9048 \\
& $K_{3 \mathrm{~d}}\left(\mathrm{mg}\left(\mathrm{g}^{-1} \mathrm{~min}^{-1 / 2}\right)\right)$ & 0.2141
\end{tabular}

isotherm model describes a multilayer adsorption on heterogeneous surfaces. ${ }^{49}$ The Temkin model has a factor that reveals the interaction between the adsorbate and adsorbent. ${ }^{45}$ The equations of Langmuir (12), Freundlich (13), and Temkin models (14) are expressed as follows: ${ }^{35,50}$

$$
\begin{gathered}
q_{\mathrm{e}}=q_{\mathrm{m}} K_{\mathrm{L}} C_{\mathrm{e}} /\left(1+K_{\mathrm{L}} C_{\mathrm{e}}\right) \\
q_{\mathrm{e}}=K_{\mathrm{F}} C_{\mathrm{e}}{ }^{1 / n} \\
q_{\mathrm{e}}=B \ln K_{\mathrm{T}}+B \ln C_{\mathrm{e}}
\end{gathered}
$$

where $q_{\mathrm{m}}\left(\mathrm{mg} \mathrm{g}^{-1}\right)$ is the maximum adsorption capacity; $C_{\mathrm{e}}(\mathrm{mg}$ $\mathrm{L}^{-1}$ ) is the equilibrium concentration of the solution; and $n$ is the empirical index. $K_{\mathrm{L}}\left(\mathrm{L} \mathrm{mg}^{-1}\right)$ and $K_{\mathrm{F}}$ are the indicators of adsorption capacity for Langmuir and Freundlich models, respectively. $B$ and $K_{\mathrm{T}}\left(\mathrm{g} \mathrm{L}^{-1}\right)$ are the parameters of Temkin model.

Fig. 8a-c showed the linear fitting of the isothermal adsorption models of PNP on PLB. Table 3 showed the fitting results of isothermal adsorption equations. The correlation coefficients of Langmuir isotherm adsorption model $\left(R^{2}=\right.$ 0.9948-0.9981) were higher than those of Freundlich isotherm adsorption model $\left(R^{2}=0.9329-0.9647\right)$ and Temkin isotherm adsorption model $\left(R^{2}=0.9922-0.9948\right)$, and the difference of $q_{\mathrm{m} \text {,cal }}$ and $q_{\mathrm{m} \text {,exp }}$ was small. Thus, the PNP adsorption on PLB 

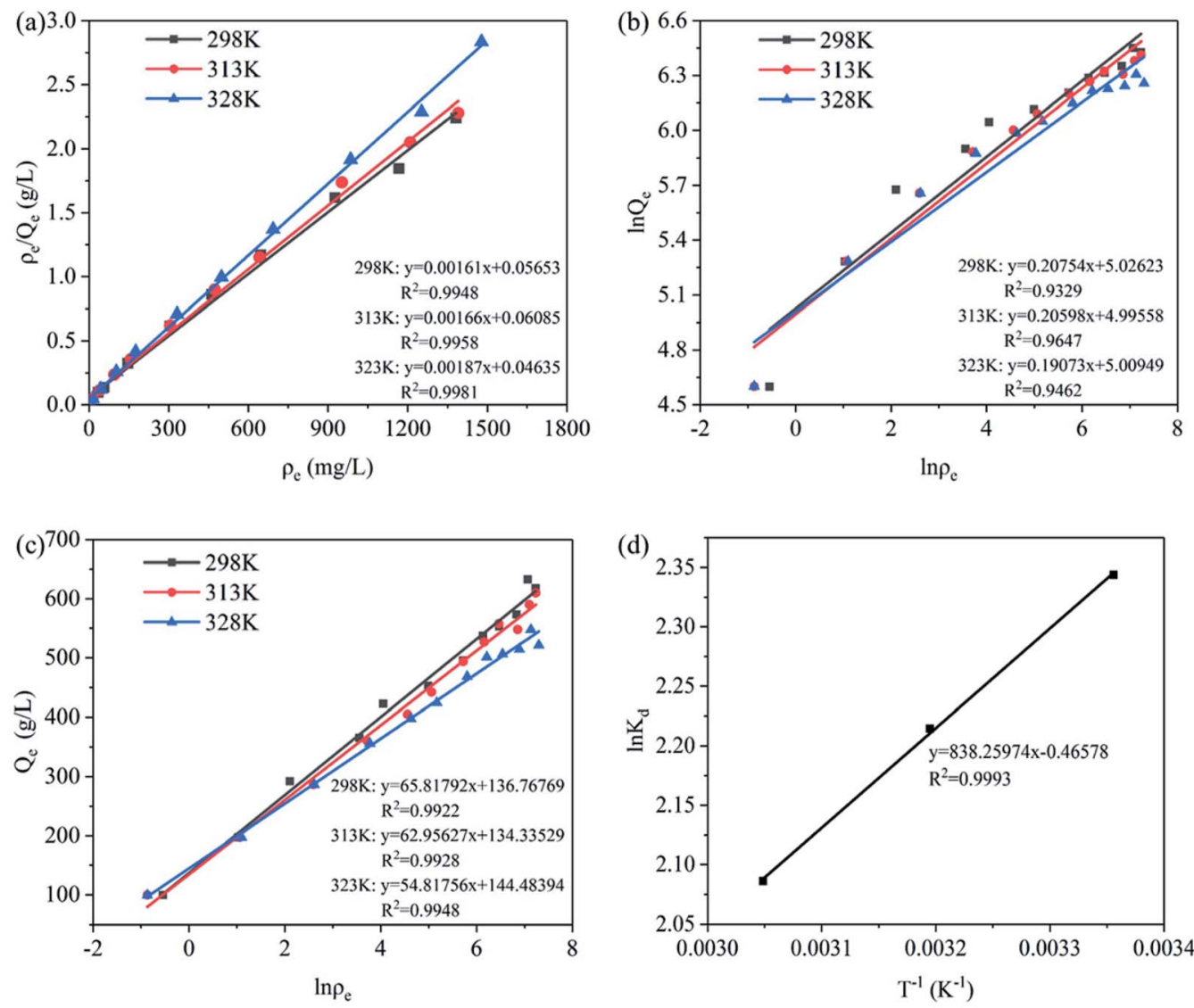

Fig. 8 Linear fitting of the isothermal adsorption models of PNP on PLB: Langmuir isothermal adsorption model (a), Freundlich isothermal adsorption model (b), and Temkin isothermal adsorption model (c); In $K_{d} v s . T^{-1}$ for PNP adsorption on PLB (d).

was more consistent with the Langmuir isotherm adsorption model in the range of the experimental concentration, suggesting that the PNP adsorption on PLB occurred in a monolayer. In addition, Table 3 showed that the maximum adsorption was affected by reaction temperature. As the temperature increased from $298 \mathrm{~K}$ to $328 \mathrm{~K}$, the adsorption capacity of PNP decreased from $622.73 \mathrm{mg} \mathrm{g}^{-1}$ to $547.68 \mathrm{mg} \mathrm{g}^{-1}$.

Table 3 Parameters of Langmuir, Freundlich and Temkin model for the PNP adsorption on PLB

\begin{tabular}{llccc}
\hline \multirow{5}{*}{ Model } & \multicolumn{3}{c}{ Temperature } \\
\cline { 3 - 5 } Langmuir & $q_{\mathrm{m}, \exp }\left(\mathrm{mg} \mathrm{g}^{-1}\right)$ & 622.73 & 590.09 & 547.68 \\
& $q_{\mathrm{m}, \mathrm{cal}^{-1}}\left(\mathrm{mg} \mathrm{g}^{-1}\right)$ & 621.12 & 602.41 & 534.76 \\
& $K_{\mathrm{L}}\left(\mathrm{L} \mathrm{mg}^{-1}\right)$ & 0.0285 & 0.0273 & 0.0403 \\
& $R^{2}$ & 0.9948 & 0.9958 & 0.9981 \\
& $R_{\mathrm{L}}$ & 0.0191 & 0.0199 & 0.0136 \\
Freundlich & $1 / n$ & 0.2075 & 0.2060 & 0.1907 \\
& $K_{\mathrm{F}}$ & 152.36 & 147.76 & 149.83 \\
& $R^{2}$ & 0.9329 & 0.9647 & 0.9462 \\
Temkin & $K_{\mathrm{T}}\left(\mathrm{g} \mathrm{L} \mathrm{L}^{-1}\right)$ & 7.998 & 8.447 & 13.953 \\
& $\mathrm{~B}$ & 65.8179 & 62.9563 & 54.8176 \\
& $R^{2}$ & 0.9922 & 0.9928 & 0.9948
\end{tabular}

Thus, the adsorption process was an exothermic reaction, and increased the temperature could be unprofitable for adsorption.

In addition, an essential factor of Langmuir isotherm is separation factor $\left(R_{\mathrm{L}}\right)$, which could be used to confirm whether adsorption is favorable. $R_{\mathrm{L}}$ is expressed as follows: ${ }^{51}$

$$
R_{\mathrm{L}}=1 /\left(1+K_{\mathrm{L}} C_{0}\right)
$$

where $K_{\mathrm{L}}$ represents the Langmuir adsorption isotherm constant, and $C_{0}\left(\mathrm{mg} \mathrm{L}^{-1}\right)$ represents the maximum concentration of adsorbate in the original solution before adsorption treatment. $R_{\mathrm{L}}$ reveals the adsorption tendency: unfavorable $\left(R_{\mathrm{L}}>\right.$ 1 ), favorable $\left(0<R_{\mathrm{L}}<1\right)$, and linear $\left(R_{\mathrm{L}}=1\right) .{ }^{52}$ The smaller the $R_{\mathrm{L}}$ had the greater affinity between the adsorbent and adsorbate. ${ }^{53}$ In this study, $R_{\mathrm{L}}$ values were between 0 and 1 (Table 3 ), indicating that the adsorption reaction proceeded favorably, and the affinity between PNP and PLB was strong.

To investigate the effect of temperature on adsorption, the thermodynamics of adsorption processes were estimated by using eqn (16)-(19): ${ }^{54}$

$$
\begin{gathered}
\Delta G=-R T \ln K_{\mathrm{d}} \\
\Delta G=\Delta H-T \Delta S \\
K_{\mathrm{d}}=q_{\mathrm{e}} / C_{\mathrm{e}}
\end{gathered}
$$


Table 4 Thermodynamic parameters for PNP adsorption on PLB

\begin{tabular}{lllll}
\hline$T(\mathrm{~K})$ & $\begin{array}{l}\Delta G \\
(\mathrm{~kJ} \mathrm{~mol})\end{array}$ & $\begin{array}{l}\Delta H \\
\left(\mathrm{~kJ} \mathrm{~mol}^{-1}\right)\end{array}$ & $\begin{array}{l}\Delta S \\
\left(\mathrm{~J}\left(\mathrm{~mol}^{-1} \mathrm{~K}^{-1}\right)\right)\end{array}$ & $R^{2}$ \\
\hline 298 & -5.811 & -6.969 & -3.872 & 0.9993 \\
313 & -5.752 & & & \\
328 & -5.694 & & &
\end{tabular}

$\ln K_{\mathrm{d}}=\Delta S / R-\Delta H / R T$

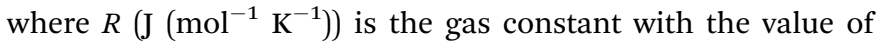
8.314, $T(\mathrm{~K})$ is the absolute temperature, and $K_{\mathrm{d}}\left(\mathrm{L} \mathrm{g} \mathrm{g}^{-1}\right)$ is the adsorption equilibrium constant.

The correlation coefficient of the thermodynamic study was obtained from Fig. $8 \mathrm{~d}$. Table 4 illustrated that $\Delta H$ was negative, confirming that PNP adsorption was an exothermic process and in agreement with the results from Table 3. $\Delta H$ value could be divided into physical adsorption (2.1-20.9 $\mathrm{kJ} \mathrm{mol}^{-1}$ ) and

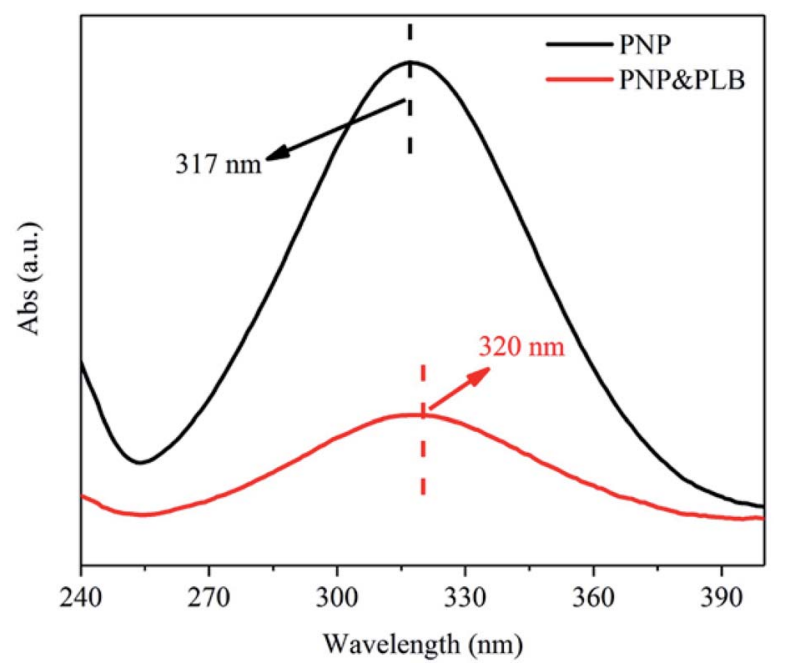

Fig. 9 The UV adsorption spectra of PNP and mixed solution (PNP\&PLB). chemical adsorption (20.9-418.4 $\left.\mathrm{kJ} \mathrm{mol}^{-1}\right){ }^{55}$ In this experiment, $\Delta H\left(6.969 \mathrm{~kJ} \mathrm{~mol}^{-1}\right)$ was relatively small, indicating that no strong force (such as chemical bond force) existed in adsorption, and the main participating forces might be $\pi-\pi$ interaction, hydrogen bonding force, and hydrophobic interaction. This was consistent with the discussion in Section 3.2. In addition, the value of $\Delta S$ was negative, indicating that the activity of PNP after adsorption on PLB was limited, and the arrangement between molecules became orderly, then the degree of chaos was reduced. Therefore, PNP adsorption on PLB was an entropy reduction process. Furthermore, $\Delta G$ with a negative value, which embodied the adsorption driving force, indicated that the adsorption process was spontaneous. Then the adsorption was unfavorable at high temperature, because the absolute value of $\Delta G$ decreased with the increase of temperature, suggesting that adsorption was unfavorable at high temperature.

\subsection{Adsorption mechanism}

The PLB provided a larger specific surface area and abundant pores, thus there existed enough hydrophobic sites for PNP adsorption by hydrophobic interaction. ${ }^{45}$ In addition, based on the FTIR analysis of PLB, there existed some functional groups on the PLB, such as ether groups, hydroxyl groups, aromatic rings and carboxyl groups. These functional groups may offer additional sites for PNP removal, which through hydrogen bonding between the hydroxyl groups or carboxyl groups on PLB and the hydroxyl, nitro groups of PNP, and through $\pi-\pi$ interaction between the aromatic rings on PLB and PNP. The UV adsorption spectra confirmed the $\pi-\pi$ interaction between PNP and PLB (Fig. 9). The main adsorption peak of PNP was presented at $317 \mathrm{~nm}$, and the peak shifted from $317 \mathrm{~nm}$ to $320 \mathrm{~nm}$ as PLB was added. The red-shift of the main adsorption peak indicated that there existed $\pi-\pi$ interaction between PNP and PLB. ${ }^{56}$ However, the $\pi$ electrons from the basal planes of PLB could be removed by the carboxyl groups, which led to a weaker $\pi-\pi$ interaction. ${ }^{35}$ Furthermore, if the hydrogen bonding was the main interaction, the $\mathrm{pH}$ of the maximum PNP adsorption capacity should be around $\mathrm{pH}_{\mathrm{PZC}} \cdot{ }^{20}$ Consequently, the

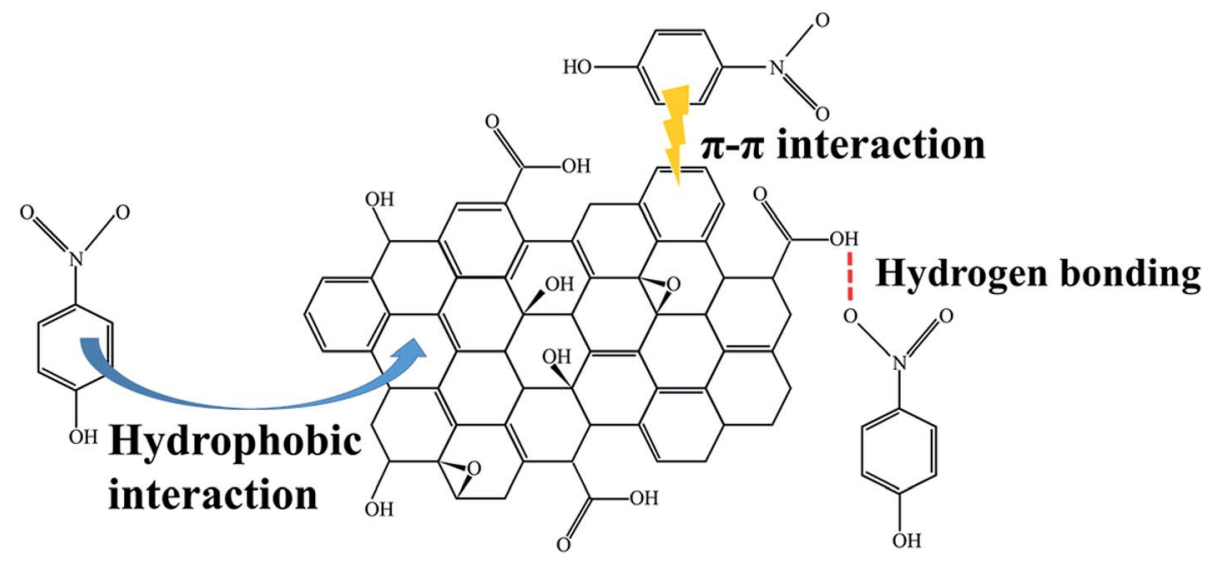

Fig. 10 Schematic diagram for the adsorption mechanism of PNP on PLB. 

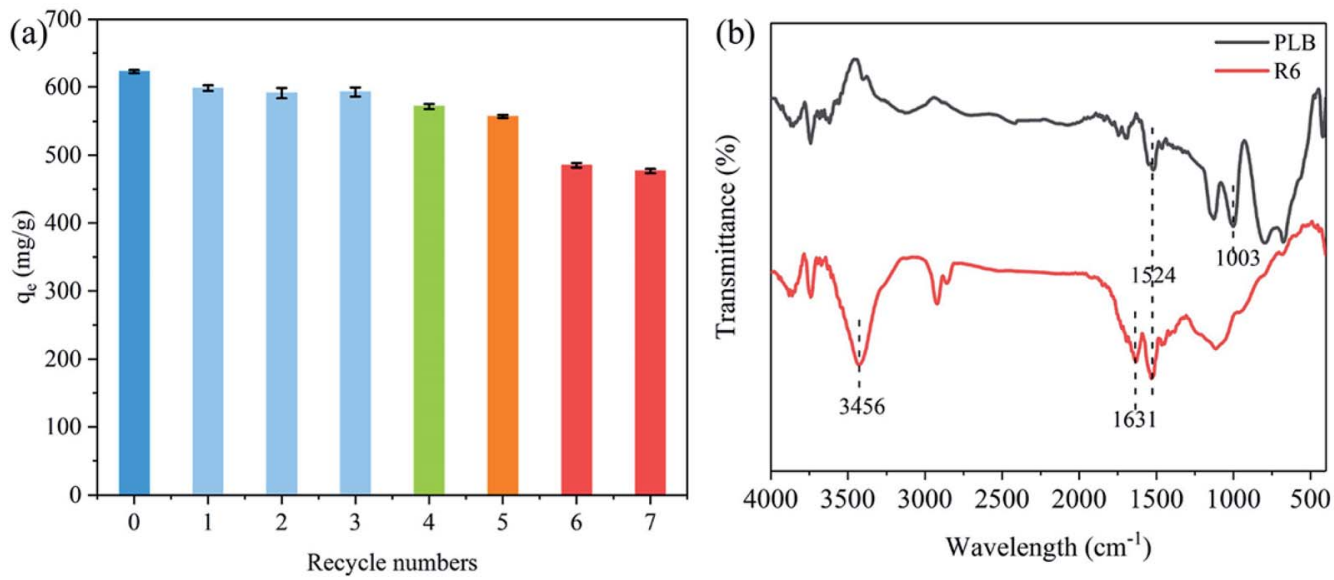

Fig. 11 The relationship between recycle numbers and adsorption capacity (a); The FTIR spectra of PLB and the sixth regeneration PLB (R6) (b).

optimized $\mathrm{pH}$ was lower than $\mathrm{pH}_{\mathrm{PZC}}$, causing $\mathrm{PNP}$ adsorption on PLB was mainly attributed to hydrophobic interaction. Therefore, the adsorption mechanism of PNP on PLB was presented in Fig. 10.

\subsection{Regeneration}

Fig. 11a showed the PNP adsorption capacity of each recycled generation. The adsorption capacity initially decreased from $622.73 \mathrm{mg} \mathrm{g}^{-1}$ (original biochar) to $571.98 \mathrm{mg} \mathrm{g}^{-1}$ (R4). Then, PLB still performed high adsorption capacity for the fifth regeneration ( $557.05 \mathrm{mg} \mathrm{g}^{-1}$ ), and the adsorption capacity was approximately $90 \%$ of the original biochar. Nevertheless, the PNP adsorption had a sharp decline to $485.01 \mathrm{mg} \mathrm{g}^{-1}$ as the number of regenerations increased, leading to a decrease in adsorption capacity ( $78 \%$ of the original biochar).

The textural parameters and FTIR spectra were analyzed to determine the causes for the decrease in adsorption capacity after regeneration. Table 5 showed that the micropores pore volume of R4 and R6 were similar but small compared with that of PLB. These results suggested that the blockage of PLB's micropores could be a cause for the decrease in adsorption capacity of the recycled biochar. However, the substantial drop for R6 could not be explained. There may be other reasons that affect the adsorption capacity of recycled biochar. Fig. 11b showed that the band at $3456 \mathrm{~cm}^{-1}$ of $\mathrm{R} 6$ was related to the $\mathrm{O}-\mathrm{H}$ stretching vibration peak of phenolic hydroxyl, and the bands at $1631 \mathrm{~cm}^{-1}$ and $1524 \mathrm{~cm}^{-1}$ was the aromatic $\mathrm{C}=\mathrm{C}$ stretching

Table 5 The textural parameters of original PLB and recycled PLB (R4 and R6)

\begin{tabular}{llll}
\hline & \multicolumn{2}{l}{ Pore volume, $\left(\mathrm{cm}^{3} \mathrm{~g}^{-1}\right)$} \\
\cline { 2 - 4 } Carbon material & $V_{\text {tot }}$ & $V_{\text {mac\&mes }}$ & $V_{\text {mic }}$ \\
\hline PLB & 0.94 & 0.23 & 0.71 \\
R4 & 0.88 & 0.26 & 0.62 \\
R6 & 0.85 & 0.25 & 0.60
\end{tabular}

vibration, ${ }^{38}$ respectively. This indicated that some PNP molecules blocked the pores and could not be washed away by $\mathrm{NaOH}$ and distilled water during the regeneration process. In addition, the band at $1003 \mathrm{~cm}^{-1}$ of R6 disappeared compared with that of PLB (Fig. 11b), indicating that hydroxyl groups and carboxyl groups were deactivated during the cleaning process. This might be the reason for the significant decrease in the adsorption of the recycled biochar. Therefore, these results indicated that a part of the micropores on the biochar was gradually blocked with each regeneration, and the deactivation of oxygen-containing functional groups became the main cause after several times of regeneration.

\section{Conclusions}

In this research, Platanus leaves were successfully produced into a biochar with good adsorption capacity and high reusability. The biochar had a well-developed porous structure with large specific surface area $\left(1792.38 \mathrm{~m}^{2} \mathrm{~g}^{-1}\right)$. There were oxygencontaining functional groups such as $-\mathrm{OH},-\mathrm{COOH}$ and $-\mathrm{C}-$ O-C on the biochar surface, which were beneficial to the adsorption of PNP. Furthermore, the study on adsorption mechanism indicated that PNP adsorption was mainly attributed to hydrophobic interaction, followed by the role of hydrogen bonding and $\pi-\pi$ interaction. In adsorption process, PNP adsorption on PLB was a spontaneous exothermic reaction which was more in line with pseudo-secondary kinetic model and Langmuir model, and the maximum adsorption capacity for PNP was $622.73 \mathrm{mg} \mathrm{g}^{-1}$ at $298 \mathrm{~K}$. In regeneration process, the adsorption capacity of PLB still reached $485.01 \mathrm{mg} \mathrm{g}^{-1}$ after the seven regenerations. In addition, pore blockage and deactivation of oxygen functional groups could be the causes for the decrease in PNP adsorption of the recycled biochar.

\section{Conflicts of interest}

There are no conflicts to declare. 


\section{Acknowledgements}

This work was supported by the Key Research and Development Plan of Shandong Province (grant no. 2017GGX202010); the Higher Education Science and Technology Project of Shandong Province (grant no. J18KA023); the International Cooperation Research Project of Qilu University of Technology (grant no. QLUTGJHZ2018003) and the Project Supported by the Foundation of State Key Laboratory of Biobased Material and Green Papermaking, Qilu University of Technology, Shandong Academy of Sciences (Grant No. ZZ20190108).

\section{References}

1 J. Yang, B. Pan, H. Li, S. Liao, D. Zhang, M. Wu and B. Xing, Environ. Sci. Technol., 2015, 50, 694-700.

2 S. Bae, S. Gim, H. Kim and K. Hanna, Appl. Catal., B, 2016, 182, 541-549.

3 C. Shi, Y. Li, H. Feng, S. Jia, R. Xue, G. Li and G. Wang, Chem. Res. Chin. Univ., 2018, 34, 39-43.

4 G. Xue, M. Gao, Z. Gu, Z. Luo and Z. Hu, Chem. Eng. J., 2013, 218, 223-231.

5 Y. Sun, J. Zhou, W. Cai, R. Zhao and J. Yuan, Appl. Surf. Sci., 2015, 349, 897-903.

6 P. Yu, Z. Chang, Y. Ma, S. Wang, H. Cao, H. Chao and H. Liu, Sep. Purif. Technol., 2009, 70, 199-206.

7 C. S. Rodrigues, R. A. Borges, V. N. Lima and L. M. Madeira, J. Environ. Manage., 2018, 206, 774-785.

8 S. R. Subashchandrabose, K. Venkateswarlu, K. Krishnan, R. Naidu, R. Lockington and M. Megharaj, J. Hazard. Mater., 2017, 347, 176-183.

9 X. Wang, C. Zhao and J. Huang, J. Nanosci. Nanotechnol., 2013, 13, 2218-2223.

10 A. S. Dos, M. F. Viante, D. J. Pochapski, A. J. Downs and C. Almeida, J. Hazard. Mater., 2018, 355, 136-144.

11 T. Chen, F. Liu, C. Ling, J. Gao, C. Xu, L. Li and A. Li, Environ. Sci. Technol., 2013, 47, 13652-13660.

12 L. Yang, S. Luo, Y. Li, Y. Xiao, Q. Kang and Q. Cai, Environ. Sci. Technol., 2010, 44, 7641-7646.

13 Z. Guo, J. Fan, J. Zhang, Y. Kang, H. Liu, L. Jiang and C. Zhang, J. Taiwan Inst. Chem. Eng., 2016, 58, 290-296.

14 Z. Guo, L. Xu, C. Liu, F. Sun, Y. Kang and S. Liang, Desalin. Water Treat., 2016, 57, 21957-21967.

15 W. Li, X. Gong, K. Wang, X. Zhang and W. Fan, Bioresour. Technol., 2014, 165, 166-173.

16 X. Gong, W. Li, D. Zhang, W. Fan and X. Zhang, Int. Biodeterior. Biodegrad., 2015, 102, 256-264.

17 G. Zolfaghari, Chem. Eng. J., 2016, 283, 1424-1434.

18 K. Nakagawa, S. Mukai, K. Tamura and H. Tamon, Chem. Eng. Res. Des., 2007, 85, 1331-1337.

19 N. Rambabu, R. Azargohar, A. Dalai and J. Adjaye, Fuel Process. Technol., 2013, 106, 501-510.

20 P. Wang, L. Tang, X. Wei, G. Zeng, Y. Zhou, Y. Deng, J. Wang, Z. Xie and W. Fang, Appl. Surf. Sci., 2017, 392, 391-401.

21 H. Zheng, W. Guo, S. Li, Y. Chen, Q. Wu, X. Feng, R. Yin, S. Ho, N. Ren and J. Chang, Bioresour. Technol., 2017, 244, 1456-1464.
22 B. Sajjadi, T. Zubatiuk, D. Leszczynska, J. Leszczynski and W. Y. Chen, Rev. Chem. Eng., 2019, 35, 777-815.

23 M. Peñas-Garzón, A. Gómez-Avilés, J. Bedia, J. J. Rodriguez and C. Belver, Materials, 2019, 12, 378.

24 H. Deng, G. Li, H. Yang, J. Tang and J. Tang, Chem. Eng. J., 2010, 163, 373-381.

25 Y. Gao, S. Xu, Q. Yue, Y. Wu and B. Gao, J. Taiwan Inst. Chem. Eng., 2016, 61, 327-335.

26 J. Li, K. Han and S. Li, J. Mater. Sci.: Mater. Electron., 2018, 29, 8480-8491.

27 Q. Li, Y. Qi and C. Gao, J. Cleaner Prod., 2015, 86, 424-431.

28 M. El Gamal, H. A. Mousa, M. H. El-Naas, R. Zacharia and S. Judd, Sep. Purif. Technol., 2018, 197, 345-359.

29 P. Lu, H. Lin, W. Yu and J. Chern, J. Taiwan Inst. Chem. Eng., 2011, 42, 305-311.

30 P. C. Bhomick, A. Supong, M. Baruah, C. Pongener and D. Sinha, Sustainable Chem. Pharm., 2018, 10, 41-49.

31 H. Ma, Z. Liu, X. Wang, C. Zhang and R. Jiang, J. Renewable Sustainable Energy, 2017, 9, 044105.

32 T. R. Bastami and M. H. Entezari, Chem. Eng. J., 2012, 210, 510-519.

33 H. Ma, Z. Chen, X. Wang, Z. Liu and X. Liu, J. Renewable Sustainable Energy, 2019, 11, 024102.

34 Y. Wu, J. Cao, X. Zhao, Z. Hao, Q. Zhuang, J. Zhu, X. Wang and X. Wei, Electrochim. Acta, 2017, 252, 397-407.

35 A. Fisal, W. M. A. W. Daud, M. A. Ahmad and R. Radzi, Chem. Eng. J., 2011, 178, 461-467.

36 S. A. Sadeek, N. A. Negm, H. H. Hefni and M. M. A. Wahab, Int. J. Biol. Macromol., 2015, 81, 400-409.

37 J. Kong, Q. Yue, L. Huang, Y. Gao, Y. Sun, B. Gao, Q. Li and Y. Wang, Chem. Eng. J., 2013, 221, 62-71.

38 B. Lai, Y. Zhang, Z. Chen, P. Yang, Y. Zhou and J. Wang, Appl. Catal., B, 2014, 144, 816-830.

39 I. M. Khan and A. Ahmad, J. Mol. Struct., 2010, 977, 189-196. 40 G. Yang and H. Jiang, Water Res., 2014, 48, 396-405.

41 M. Thommes, K. Kaneko, A. V. Neimark, J. P. Olivier, F. Rodriguez-Reinoso, J. Rouquerol and K. S. Sing, Pure Appl. Chem., 2015, 87, 1051-1069.

42 S. Ershov, F. Khelifa, P. Dubois and R. Snyders, ACS Appl. Mater. Interfaces, 2013, 5, 4216-4223.

43 W. Liu, F. Zeng, H. Jiang and X. Zhang, Chem. Eng. J., 2011, 170, 21-28.

44 L. Tang, J. Tang, G. Zeng, G. Yang, X. Xie, Y. Zhou, Y. Pang, Y. Fang, J. Wang and W. Xiong, Appl. Surf. Sci., 2015, 333, 220-228.

45 Y. Zhou, X. Liu, L. Tang, F. Zhang, G. Zeng, X. Peng, L. Luo, Y. Deng, Y. Pang and J. Zhang, J. Hazard. Mater., 2017, 333, 80-87.

46 A. Dąbrowski, P. Podkościelny, Z. Hubicki and M. Barczak, Chemosphere, 2005, 58, 1049-1070.

47 P. Rao, Z. Sun, W. Zhang, W. Yao, L. Wang and G. Ding, RSC Adv., 2015, 5, 89545-89551.

48 H. Ma, J. Yang, X. Gao, Z. Liu, X. Liu and Z. Xu, J. Hazard. Mater., 2019, 369, 550-560.

49 H. Nourmoradi, M. Avazpour, N. Ghasemian, M. Heidari, K. Moradnejadi, F. Khodarahmi, M. Javaheri and 
F. M. Moghadam, J. Taiwan Inst. Chem. Eng., 2016, 59, 244251.

50 N. Ünlü and M. Ersoz, J. Hazard. Mater., 2006, 136, 272-280.

51 D. P. Dutta, R. Venugopalan and S. Chopade, ChemistrySelect, 2017, 2, 3878-3888.

52 A. C. Martins, O. Pezoti, A. L. Cazetta, K. C. Bedin, D. A. Yamazaki, G. F. Bandoch, T. Asefa, J. V. Visentainer and V. C. Almeida, Chem. Eng. J., 2015, 260, 291-299.
53 K. Li, P. Li, J. Cai, S. Xiao, H. Yang and A. Li, Chemosphere, 2016, 154, 310-318.

54 B. A. Fil, Part. Sci. Technol., 2016, 34, 118-126.

55 C. Sun, C. Li, C. Wang, R. Qu, Y. Niu and H. Geng, Chem. Eng. J., 2012, 200-202, 291-299.

56 Y. Wei and Y. Xia, J. Environ. Sci. Water Resour., 2019, 5, 577584. 